\title{
Study and Investigate Effects of Cutting Surface in CNC Milling Process for Aluminum based on Taguchi Design Method
}

\author{
Simone Senesathit, Sanpeng Deng, Shengcheng Zhang, Yaser Mohammed Ahmed Al Rubaei, \\ Xianqi Yuan, Tong Wang, Jingle Duan \\ Tianjin University of Technology and Education, \\ Institute of Robotics and Intelligent Equipment, Tianjin 300222, \\ China
}

\begin{abstract}
The part programmer can change the program on the control itself at the machine or $\mathrm{PC}$ with instantaneous results. This flexibility is the greatest advantage of the $\mathrm{CNC}$ system and probably the key element that contributed to such a wide use of the technology in modern manufacturing in the world. CNC machine tools require less operator inputs, provide greater improvement in productivity and increase the quality of the machined part. The purpose of this paper is to conduct research of machining parameters of the machine impact on product quality and productivity of the process. Therefore the relationship between surface roughness and material removal rate has become an important part for the analysis input 3 parameters such spindle speed, feed rate and depth of cut selected as a control factors in Taguchi technique design method of response variable optimization with keeping operating dry conditons and the usage only one tool inserts constant. Which each milling operation depend on material removal rate, and surface roughness are measured. An orthogonal array of 3level was used and Minitab were performed to find out the significance of each of the input parameters on the material removal rate, surface roughness. In presenting the experimental results of Material removal rate and surface roughness using Taguchi's dynamic design of experiments is proposed for end milling operations. Experimentation is planned as per Taguchi's L(3)9 orthogonal array. Assumptions of ANOVA are discussed and carefully examined using analysis of residuals. The final results revealed that the feed rate and depth of cut are main affecting parameter of MRR. Finally, experimental confirmation was carried out to identify the effectiveness of this proposed method. Minitab offer both mean analysis as well as S/N Ratio base DOF. Minitab 18 helps to make orthogonal array.
\end{abstract}

Keywords-Taguchi design method; Material removal rate; Surface roughness; CNC End-Milling operations.

\section{INTRODUCTION}

Milling is a process that uses a milling cutter to remove material from the surface of a workpiece. The milling cutter is a rotation cutting tools, often with multiple cutting points. As opposed to drilling, where the tool is advanced along its rotation axis, the cutter in milling is usually moved perpendicular to its axis so that cutting occurs on the circumference of the cutter. As the milling cutter enters the workpiece, the cutting edges of the tool repeatedly cut into and exit from the material, shaving off chips from the workpiece with each pass. The cutting action is shear deformation; material is pushed off the workpiece in tiny clumps that hang together to a greater to form chips. CNC machine tools require less operator inputs, provide greater improvement in productivity and increase the quality of the machined part. CNC the abbreviation for Computer Numeric Control is used for that type of systems which controls the functions of a machine tool using coded instructions processed by a computer. The application of CNC to a manual machine allows its operation to become fully automated. Combining this with the use of a part program enhances the ability of the machine to perform repeat tasks with high degrees of accuracy. Preparatory functions, called G codes, are used to locate the geometry of tool movements and operating state of the machine controller; functions such as linear cutting movements, drilling operations and specifying the units of measurement [1]. Milling is the process of machining flat, curved, or irregular surface by feeding the work piece against a rotating cutter containing a number of cutting edges. Milling is the fundamental machining operation among several industrial CNC (Computer Numerical Control) machining processes. For metal removal operation end milling and face milling is mostly used. The end milling operation is associated with surface roughness and material removal rate because of some requirements such as machining efficiency, high quality surfaces, dimensional accuracy, and the process reliability [2]. End milling and face milling are broadly used in variety of manufacturing industries including automotive sectors, aerospace, where quality is vital factor in the production of slots, pockets, and precision moulds and dies [3]. As a basic machining process, milling is one of the most widely used metal removal processes in industry and milled surfaces are largely used to mate with other parts in die, aerospace, automotive, and machinery design as well as in manufacturing industries $[4,5]$. Surface roughness is an important measure of the technological quality of a product and a factor that greatly influences manufacturing cost. The mechanism behind the formation of surface roughness is very dynamic, complicated, and process dependent; it is very difficult to calculate its value through theoretical analysis [6]. Therefore, machine operators usually use "trial and error" approaches to set-up milling machine cutting conditions in order to achieve the desired surface Roughness. Obviously, the "trial and error" method is not is a repetitive and empirical process that can be very time 
consuming. The dynamic nature and widespread usage of milling operations in practice have raised a need for seeking a systematic Approach that can help to set-up milling operations in a timely manner and also to help achieve the desired surface roughness quality [7]. In order to find the optimized set of input parameters and also to identify the effect of each towards a particular output, researchers have been trying for years together [8]. The Taguchi method is a powerful experimental design tool uses simple, effective and systematic approach for deriving of the optimal machining parameters in lower time. For the milling operation different cutting tools are used to remove extra material from work piece such as carbide end mill tool (coated/uncoated), HSS tool etc.

\section{BACKGROUND OF TAGUCHI DESIGN}

Taguchi methods are statistical methods developed by Genichi Taguchi [9]. to improve the quality of manufactured goods and more recentl also apply to engineering, biotechnology, marketing and,advertising. Profe ssional statisticians have welcomed the goals and improvements brought about by Taguchi methods, particularly by Taguchi's development of designs for studying variation, but have criticized the inefficiency of some of Taguchi's proposals. The Taguchi method is a commonly adopted approach for optimizing design parameters. The method was originally proposed as a means of improving the quality of products through the application of statistical and engineering concepts. It is a method based on Orthogonal Array (OA) [10]. experiments, which provides much-reduced variance for the experiment resulting is optimum setting of process control parameters. Orthogonal Array (OA) provides a set of wellbalanced experiments (with less number of experimental runs) and Taguchi "s signal-to-noise ratios ( $\mathrm{S} / \mathrm{N})$, which are logarithmic functions of desired output, serves as objective function in the optimization process. This technique helps in data analysis and prediction of optimum results. In order to evaluate optimal parameter settings, Taguchi method uses a statistical measure of performance called signal-tonoise ratio. The $\mathrm{S} / \mathrm{N}$ ratio takes both the mean and the variability into account. The $\mathrm{S} / \mathrm{N}$ ratio is the ratio of the mean (Signal) to the standard deviation (Noise). The ratio depends on thequality characteristics of the product/process to be optimized. Taguchi method is a powerful tool for the design of high quality systems. It provides simple, efficient and systematic approach to optimize designs for performance, quality and cost. Taguchi method is efficient method for designing process that operates consistently and optimally over a variety of conditions. To determine the best design it requires the use of a strategically designed experiment.Taguchi approach to design of experiments in easy to adopt and apply for users with limited knowledge of statistics, hence gained wide popularity in the engineering and scientific community. The desired cutting parameters are determined based on experience or by hand book. Cutting parameters are reflected. Steps of Taguchi method are as follows:
(1) Identification of main function, side effects and failure mode.

(2) Identification of noise factor, testing condition and quality characteristics.

(3) Identification of the main function to be optimized.

(4) Identification the control factor and their levels.

(5) Selection of orthogonal array and matrix experiment.

(6) Conducting the matrix experiment.

(7) Analyzing the data, prediction of the optimum level and performance.

(8) Performing the verification experiment and planning the future action.

\section{A. Orthogonal Arrays}

Taguchi has developed a system of tabulated designs (arrays) that allow for the maximum number of main effects to be estimated in an unbiased (orthogonal) manner, with a minimum number of runs in the experiment. Orthogonal arrays are used to systematically vary and test the different levels of each of the control factors. Commonly used OAs includes the L4, L9, L12, L18, and L27. The columns in the $\mathrm{OA}$ indicate the factor and its corresponding levels, and each row in the OA constitutes an experimental run which is performed at the given factor settings. Typically either 2 or 3 levels are chosen for each factor. Selecting the number of levels and quantities properly constitutes the bulk of the effort in planning robust design experiments. If there is an experiment having 3 factors which have three values, then total number of experiment is 27 . Then results of all experiment will give $100 \%$ accurate results. In comparison to above method the Taguchi orthogonal array make list of nine experiments in a particular order which cover all factors. Those nine experiments will give $99.96 \%$ accurate result. By using this method number of experiments reduced to 9 instead of 27 with almost same accuracy.

\section{B. Signal to Noise Ratio and Pareto ANOVA Approach}

The $\mathrm{S} / \mathrm{N}$ ratio developed by Dr. Taguchi is a performance measure to choose control levels that best cope with noise. The $\mathrm{S} / \mathrm{N}$ ratio [11]. takes both the mean and the variability into account. In its simplest form, the $\mathrm{S} / \mathrm{N}$ ratio is the ratio of the mean (signal) to the standard deviation (noise). The $\mathrm{S} / \mathrm{N}$ equation depends on the criterion for the quality characteristic to be optimized. There are three standard types of $\mathrm{S} / \mathrm{N}$ ratios depending on the desired performance response.

1) Larger The Better (For Making The System Response As Large As Possible):

$$
\mathrm{S} / \mathrm{N}_{\mathrm{L}}=-10 \log \left(\frac{1}{\mathrm{n}} \sum_{i=1}^{n} 1 / Y_{i}^{2}\right)
$$

2) Nominal The Best (For Reducing Variability Around A Target):

$$
\mathrm{S} / \mathrm{N}_{\mathrm{N}}=10 \log \left(\mathrm{Y}^{2} / \mathrm{S}^{2}\right)
$$

3) Smaller The Better (For Making The System Response As Small As Possible):

$$
\mathrm{S} / \mathrm{N}_{\mathrm{S}}=-10 \log \left(\frac{1}{n} \sum_{i=1}^{n} Y_{i}^{2}\right)
$$


Table. 1 Orthogonal array.

\begin{tabular}{|l|l|l|}
\hline Signal to Noise ratio & \multicolumn{1}{|c|}{ Use when the goal is to } & \multicolumn{1}{c|}{ S/N Ratio Formula } \\
\hline Larger is better & Maximize the response & $\mathrm{S} / \mathrm{N}=-10 \times \log 10\left(\operatorname{Sum}\left(1 / \mathrm{Y}^{2}\right) / \mathrm{n}\right)$ \\
\hline Nominal is best & Standard deviations only & $\mathrm{S} / \mathrm{N}=-10 \times \log 10\left(\mathrm{~S}^{2}\right)$ \\
\hline Nominal is best & Standard deviations only & $\mathrm{S} / \mathrm{N}=10 \times \log 10\left(\mathrm{Ybar}^{2} / \mathrm{S}^{2}\right)$ \\
\hline Smaller is better & Minimize the response & $\mathrm{S} / \mathrm{N}=-10 \times \log 10\left(\mathrm{Sum}\left(\mathrm{Y}^{2}\right) / \mathrm{n}\right)$ \\
\hline
\end{tabular}

"Where $\mathrm{n}$ is the number of observations, $\mathrm{y}$ is the observed data". These SN ratios are derived from the quadratic loss function and are expressed in a decibel scale. Once all of the $\mathrm{SN}$ ratios have been computed for each run of an experiment, Taguchi advocates a graphical approach to analyze the data. In the graphical approach, the $\mathrm{SN}$ ratios are plotted for each factor against each of its levels. Finally, confirmation tests should be run at the "optimal" product settings to verify that the predicted performance is actually realized.

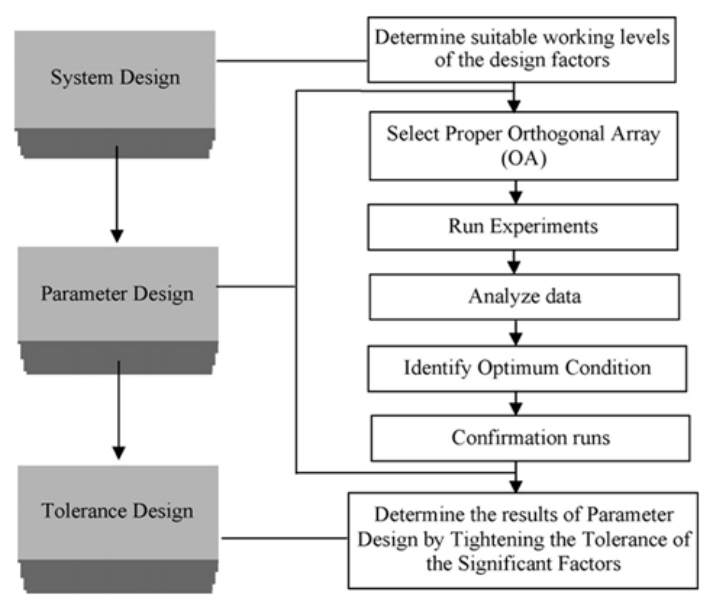

Fig. 1 Taguchi design method.

The Procedure of the Taguchi design method is shown in Fig. 1 description Objective of quality engineering is to make products that are robust in respect of all noise factors [4]. So, Taguchi created standard orthogonal array to accommodate as many factors as possible into control factor selection stage to identify non-significant variables in the earliest opportunity. Taguchi used the signal-to-noise $(\mathrm{S} / \mathrm{N})$ ratio as the measurable value of the quality characteristics of the choice. This shows that the engineering systems can behave in a way such that the manipulated production factors can be divided into three categories:

1) Control factors, (factors that affect the process variability as measured by the $\mathrm{S} / \mathrm{N}$ ratio)

2) Signal factors (factors that do not influence the $S / N$ ratio or process mean).

3) Factors (factors that do not affect the $\mathrm{S} / \mathrm{N}$ ratio or process mean).

\section{OBJECTIVE OF STUDY}

In this study, the Taguchi parameter design phase is the most important design phase and served the objective of determining the optimal end-milling parameters to achieve the lowest surface roughness and Material removal rate in cutting surface Aluminum alloy-8011h14 50mm x 50mm x $50 \mathrm{~mm}$ under varying end-milling parameter conditions. The following are the questions considered in this study the relationship between the control factors (spindle speed, feed rate and depth of cut,) and output response factors (MRR and surface roughness).The optimal conditions of the end-milling parameters for surface roughness and material removal rate.

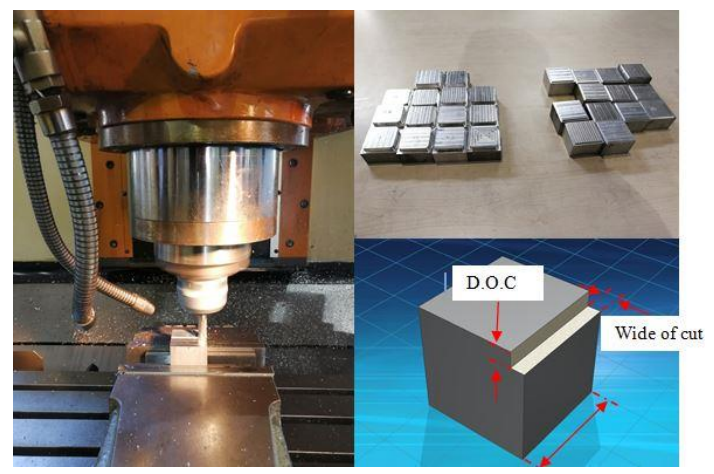

Fig. 2 Cutting surface by CNC End-milling aluminum alloy-8011h14.

\section{SURFACE FINISHING IN MACHINING}

a. Ideal surface roughness

b. Natural surface roughness

2.1 Measurement of surface roughness

(1) Direct measurement methods. (2) Comparison based techniques. (3) Non-contact methods. (4) On-process measurement.

2.2 Factors Influencing surface roughness in milling.

(1) Spindle speed: (2) Feed rate: (2) Depth of cut:

2.3 Experimental details

In this experimental process, 9 different combinations of milled lines with $4 \mathrm{~mm}$ width were made by performing an end-milling operation (dry condition) in CNC Milling Process for Aluminum alloy-8011h14 as shown in Figure: 1.2.The milling operation processes were performed in a 3axis $(\mathrm{X}, \mathrm{Y}, \mathrm{Z})$ based on FDNC 86 CNC milling Centre. Meanwhile, the cutting tool used is the NKO end-milling tool with four flutes (dia, $12 \mathrm{~mm}$ ). The surface roughness measurement was done by using a portable surface roughness tester TR200 measures $\mathrm{RN}(\mathrm{lm})$. Therefore the parameter based on S/N Ratio analysis. Minitab offer both mean analysis as well as S/N Ratio base DOF. Minitab 18 helps to make orthogonal array. The snap shot of software application shown in figure while doing analysis work. 


\section{EXPERIMENTAL SET UP}

\section{A. Machine Specification}

- Instrument name: Makino FDNC 86 vertical profile milling machine MAKINO FDNC 86.

- Manufacturer: Japan Makino Machine Tool Manufacturing Co., Ltd.

- $\quad$ Production date: 1.1995.

- Main Specifications: Makino FDNC 86

- Control system: makinocommand55N FANUC Series 15MEH-B-4.

- Spindle motor power: AC $11 \mathrm{KW}$ (30 points) / 75KW (Continuous).

- Spindle speed: 10 3000 rpm.

- Table travel: 850x600x560mm load.

- Capacity: $1500 \mathrm{~kg}$.

- Usage:

Makino FDNC86 vertical copy milling machine is an advanced product of the Japanese Makino machine tool manufacturing company in the 1990s. The large amount of machine tools is characterized by the contouring function of the product. Through the cooperation of the contoured contacts and the cutting tools, the product contours of equal proportion or unequal proportion can be performed. The $\mathrm{X}$, $\mathrm{Y}$ and $\mathrm{Z}$ axes of the machine tool can realize three-axis linkage, and there are many work piece origin setting functions. It can process three-dimensional complex curved surfaces such as whole parts, plane contour parts, mold cavities and cores, for convenient and fast processing. High precision and complex work pieces provide protection. The machine supporting software includes Pro/E, UG, GATA, MasterCAM, etc. It can be used to automatically program and simulate the work piece.

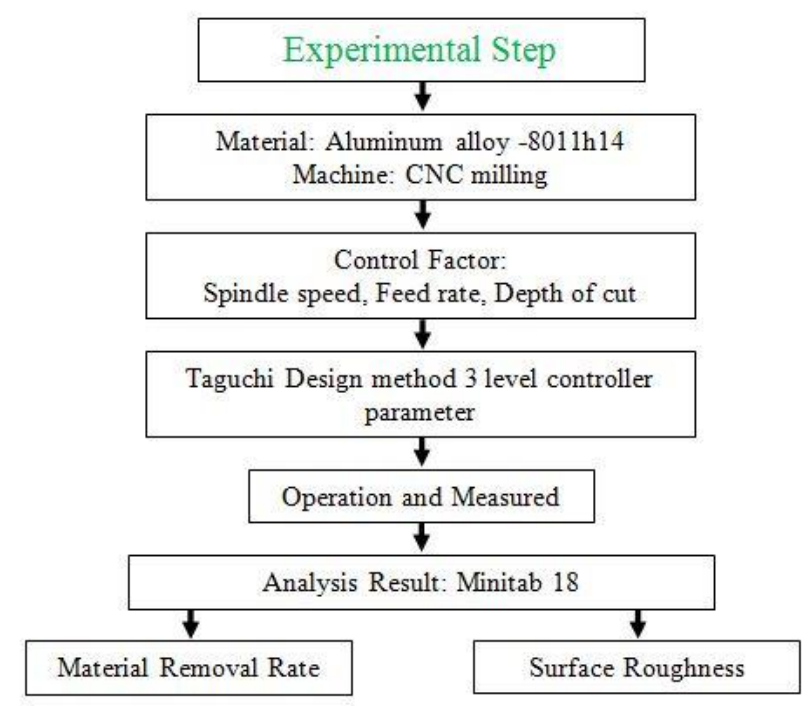

Fig. 3 CNC Milling Machine Operation experiment.

Table. 2 Parameters, codes, and level values used for orthogonal array.

\begin{tabular}{l|cccc}
\hline \multicolumn{1}{c|}{ Parameter } & Code & Level 1 & Level 2 & Level 3 \\
\hline Control factors & A & 800 & 900 & 1000 \\
Spindle speed, ss (rpm) & B & 50 & 100 & 150 \\
Feed rate, f (mm/min) & C & 0.1 & 0.2 & 0.3 \\
Depth of cut, d (mm & & & - & - \\
Response variable & - & - & - & - \\
Material removal rate (MRR) & - & - & - \\
Surface roughness RN (1m) & & & - & \\
\hline
\end{tabular}

ANOVA is a statistical technique which provides important conclusions based on analysis of the experimental data. This technique is very useful for revealing the level of significance of the influence of factor (s) or interaction between factors on a particular response. It segregates the total variability of the response into individual contributions of each of the factors and the error. The Taguchi method aims to find an optimal combination of parameters that have the smallest variance in performance. The signal tonoise $(\mathrm{S} / \mathrm{N})$ ratio measures how the response varies relative to the nominal or target value under different noise conditions. Minitab 18 software help to calculate S/N Ratio based on required response and provide Analysis of variance table and response plot for deciding significant parameter and to find (\%) percentage contribution of each parameter. Mean $\mathrm{S} / \mathrm{N}$ ratio plot gives idea about the optimum level for the factor. It is preferred to do $\mathrm{S} / \mathrm{N}$ analysis as mean sum of square may be too small in case of mean analysis. It is very accurate to judge the optimum parameter based on $\mathrm{S} / \mathrm{N}$ Ratio analysis. Minitab offer both mean analysis as well as S/N Ratio base DOF. Minitab 18 helps to make orthogonal array. The snap shot of software application shown in figure while doing analysis work. 
Table. 3 Orthogonal Array.

\begin{tabular}{|c|c|c|c|}
\hline No & S.S (r.p.m) & F.R (mm/min) & D.O.C (mm) \\
\hline 1 & 800 & 50 & 0.1 \\
\hline 2 & 800 & 100 & 0.2 \\
\hline 3 & 800 & 150 & 0.3 \\
\hline 4 & 900 & 50 & 0.2 \\
\hline 5 & 900 & 100 & 0.3 \\
\hline 6 & 900 & 150 & 0.1 \\
\hline 7 & 1000 & 50 & 0.3 \\
\hline 8 & 1000 & 100 & 0.1 \\
\hline 9 & 1000 & 150 & 0.2 \\
\hline
\end{tabular}

Table. 4 Result Table for MRR and Surface roughness.

\begin{tabular}{|c|c|c|c|c|c|}
\hline No & S.S (r.p.m) & F.R (mm/min) & D.O.C (mm) & MRR ( $\left.\mathbf{m m}^{\mathbf{3}} / \mathbf{m i n}\right)$ & RN (Im) \\
\hline 1 & 800 & 50 & 0.1 & 20 & 1.01 \\
\hline 2 & 800 & 100 & 0.2 & 80 & 1.74 \\
\hline 3 & 800 & 150 & 0.3 & 180 & 1.84 \\
\hline 4 & 900 & 50 & 0.2 & 40 & 0.98 \\
\hline 5 & 900 & 100 & 0.3 & 120 & 1.25 \\
\hline 6 & 900 & 150 & 0.1 & 60 & 2.35 \\
\hline 7 & 1000 & 50 & 0.3 & 60 & 1.49 \\
\hline 8 & 1000 & 100 & 0.1 & 40 & 1.95 \\
\hline 9 & 1000 & 150 & 0.2 & 120 & 1.04 \\
\hline
\end{tabular}

Table. 5 Response Table.

\begin{tabular}{|c|c|c|c|c|}
\hline No & MRR $\left(\mathbf{m m}^{\mathbf{3}} \mathbf{m i n}\right)$ & S/N For MRR & RN $(\mathbf{I m})$ & S/N For RN \\
\hline 1 & 20 & 26.0206 & 1.01 & -0.08643 \\
\hline 2 & 80 & 38.0618 & 1.74 & -4.81098 \\
\hline 3 & 180 & 45.1055 & 1.84 & -5.29636 \\
\hline 4 & 40 & 32.0412 & 0.98 & 0.17548 \\
\hline 5 & 120 & 41.5836 & 1.25 & -1.93820 \\
\hline 6 & 60 & 35.5630 & 2.35 & -7.42136 \\
\hline 7 & 60 & 35.5630 & 1.49 & -3.46373 \\
\hline 8 & 40 & 32.0412 & 1.95 & -5.80069 \\
\hline 9 & 120 & 41.5836 & 1.04 & -0.34067 \\
\hline
\end{tabular}

\section{B. Response Table for $S / N$ Ratios (Larger is better)}

The Taguchi method analysis: Material removal rate $\left(\mathrm{mm}^{3} / \mathrm{min}\right)$ versus spindle speed, feed rate, and depth of cut response table for signal to Noise-Ratios material removal rate larger is better main effects plot for $\mathrm{S} / \mathrm{N}$ ratios.

Table. 6 Response table for Material removal rate $\left(\mathrm{mm}^{3} / \mathrm{min}\right)$.

\begin{tabular}{c|ccc}
\hline Level & $\begin{array}{c}\text { Spindle } \\
\text { speed }(\boldsymbol{r} . \mathbf{p . m})\end{array}$ & Feed rate $(\boldsymbol{m m} / \mathbf{m i n})$ & Depth of cut (mm) \\
\hline 1 & 36.40 & 31.21 & 31.21 \\
2 & 36.40 & 37.23 & 37.23 \\
3 & 36.40 & 40.75 & 40.75 \\
Delta & 0.00 & 9.54 & 9.54 \\
Rank & 3 & 1.5 & 1.5 \\
\hline
\end{tabular}

\section{Response Table for S/N Ratios (Smaller is better)}

The Taguchi method analysis: Surface roughness $(\mathrm{lm})$ versus spindle speed, feed rate and depth of cut response table for signal to Noise-Ratios smaller is better main effects plot for $\mathrm{S} / \mathrm{N}$ ratios.

Table. 7 Response table for Surface roughness ( $1 \mathrm{~m})$.

\begin{tabular}{c|ccc}
\hline Level & $\begin{array}{c}\text { Spindle } \\
\text { speed }(\text { r.p.m) }\end{array}$ & Feed rate $(\mathbf{m m} / \mathbf{m i n})$ & Depth of cut (mm) \\
\hline 1 & -3.398 & -1.125 & -4.436 \\
2 & -3.061 & -4.183 & -1.659 \\
3 & -3.202 & -4.353 & -3.566 \\
Delta & 0.337 & 3.228 & 2.777 \\
Rank & 3 & 1 & 2 \\
\hline
\end{tabular}

From the cutting surface area and this speeds up the deformation of the surface roughness [14]. It was observed that the most effective parameter in the increase of surface roughness was deph of cut and feed rate. Because the surface roughness is a function of feed rate, an increasing feed rate caused a significant increase in the MRR values. 
Similarly, an increase in feed rate had an important effect on the increase of RN. [15]. Extremely high cutting speeds and feed rates were observed to be effective in the increase of RN. As a result, the spindle speed, feed rate and depth of cut in obtaining lower MRR and RN values. The graphs showing the effects of the control factors based on Taguchi Method (Fig. 4-6) on the changes of MRR and RN testify the results obtained from the experimental object studies.

\section{RESULT AND DISCUSSION}

ANOVA is a statistical method which is used to determine the individual individual interactions of all of the control factors in the test design. In this study, ANOVA was used to analysis the effects of spindle speed, feed rate and depth of cut.

Taguchi analysis: MRR $\left(\mathrm{mm}^{3} / \mathrm{min}\right)$, surface roughness $(\mathrm{lm})$ versus spindle speed, feed rate and depth of cut response table for signal to Noise-Ratios material removal rate larger is better and smaller is better main effects plot for $\mathrm{S} / \mathrm{N}$ ratios (Table. 3-4).
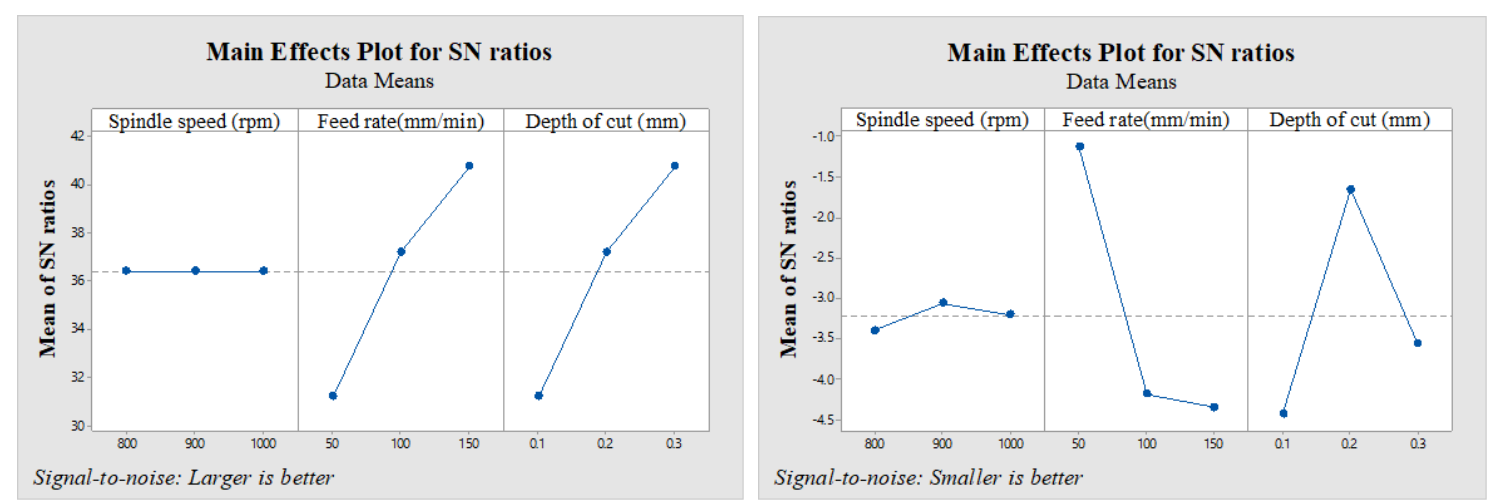

Fig. 4 Effect of process parameters on average S/N ratio for MRR and RN.
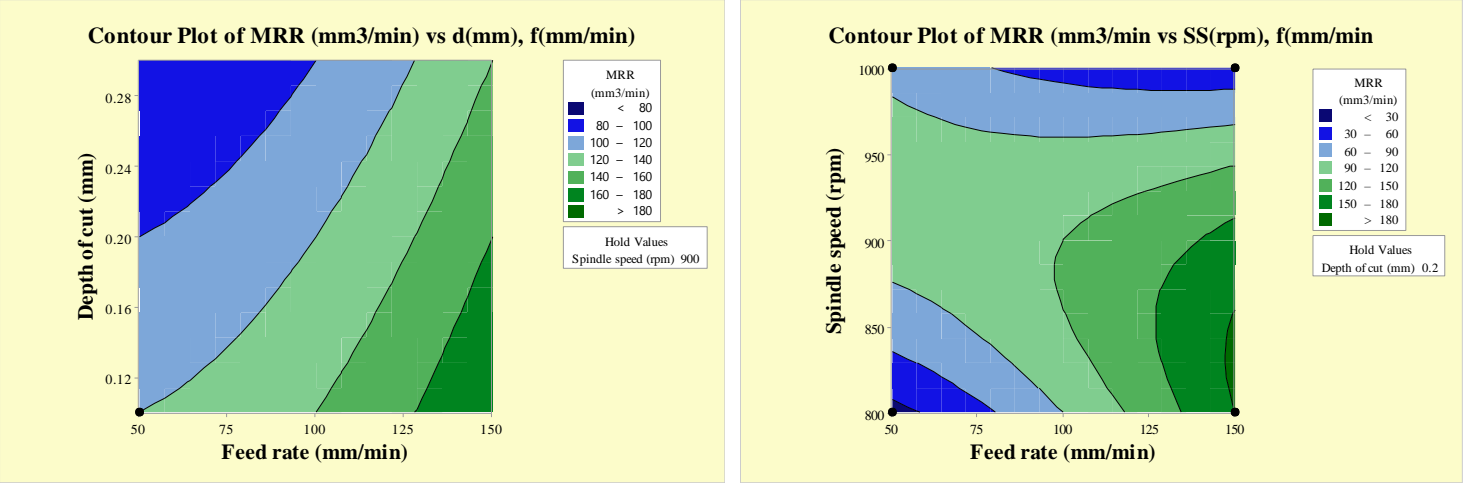

Fig. 5 Effect of the cutting parameters on MRR.
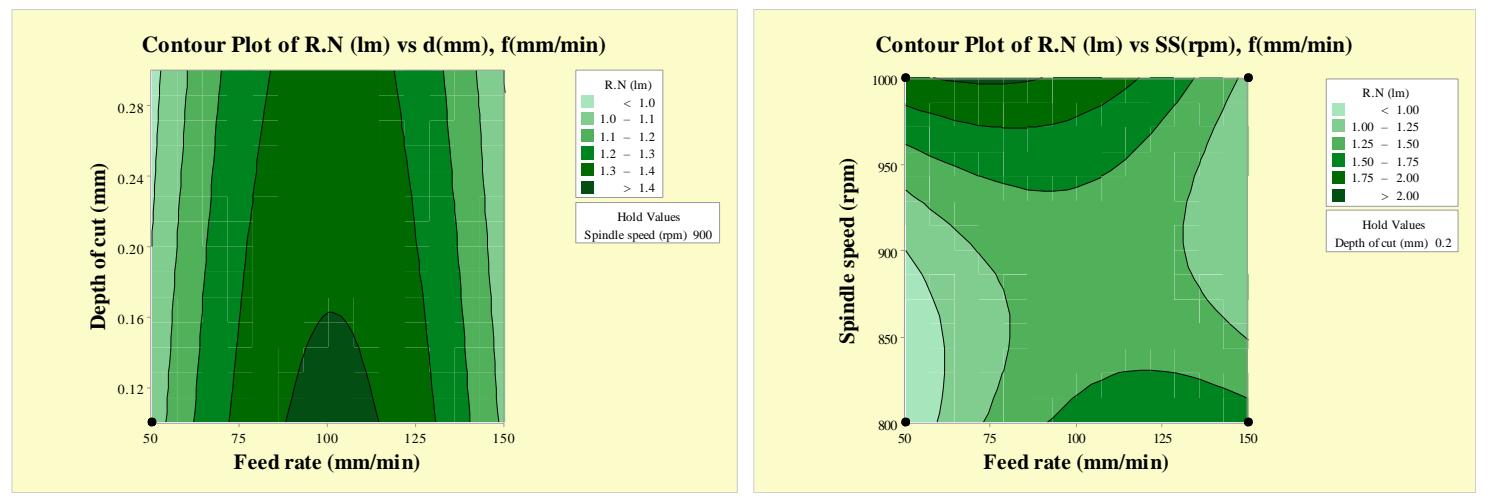

Fig. 6 Effect of the cutting parameters on RN.

From the Effect of process parameters were found rates on Material removal rate and surface roughness. The ANOVA final results for the Material removal rate and surface roughness are shown in Table. 8. This analysis was carried out a
$5 \%$ significance level and a 95\% confidence level. The significance of control factors in ANOVA is determined by comparing the $\mathrm{F}$ values of each control factor [15]. The last column of the table shows the percentage value of each parameter 
contribution which indicates the degree of influence on the process performance. According to Table. 8, the percent contributions of the $\mathrm{A}, \mathrm{B}$ and $\mathrm{C}$ factors on the Material removal rate were found to be $3.85 \%, 46.15 \%$ and $46.15 \%$ respectively. Thus, the most important factor affecting the surface roughness were feed rate and depth of cut (factor $\mathrm{B}=46.15 \%, \mathrm{C}=46.15 \%$ ). According to the ANOVA results, the percent contributions of the $\mathrm{A}, \mathrm{B}$ and $\mathrm{C}$ factors.

Table.8 Results of ANOVA for MRR and RN

\begin{tabular}{|c|c|c|c|c|c|}
\hline $\begin{array}{l}\text { Variance } \\
\text { source }\end{array}$ & $\begin{array}{c}\text { Degree of freedom } \\
\text { (DoF) }\end{array}$ & $\begin{array}{c}\text { Sum of squares } \\
(\mathrm{SS})\end{array}$ & Mean square (MS) & F ratio & $\begin{array}{c}\text { Contribution rate } \\
(\%)\end{array}$ \\
\hline \multicolumn{6}{|l|}{ MRR } \\
\hline A & 2 & 800.0 & 400.0 & 1.00 & $3.85 \%$ \\
\hline B & 2 & 9600.0 & 4800.0 & 12.00 & $46.15 \%$ \\
\hline Total & 8 & 20800.0 & - & - & $100.00 \%$ \\
\hline \multicolumn{6}{|l|}{$\mathrm{RN}$} \\
\hline A & 2 & 0.00247 & 0.001233 & 0.00 & $0.27 \%$ \\
\hline Total & 8 & 1.88040 & - & - & $100.00 \%$ \\
\hline
\end{tabular}

On Material removal rate were found to be $\mathrm{A}=3.85 \%, \quad \mathrm{~B}=46.15 \%$ and $\mathrm{C}=46.15 \%$ respectively. This showed that the most effective factor on Material removal rate were feed rate and depth of cut (factor $\mathrm{B}=46.15 \% \mathrm{C}=46.15 \%$ ). The percent of error was considerably low at $48.66 \%$ at the same time on $\mathrm{RN}$ were found to be $\mathrm{A}=0.27 \%, \mathrm{~B}=31.69 \%$ and $\mathrm{C}=19.38 \%$ respectively. This showed that the most effective factor on surface roughness was feed rate (factor $\mathrm{B}=31.69 \%$ ). The percent of error was considerably hight at $48.66 \% \mathrm{RN}$ respectively.

\section{CONCLUSIONS}

The Taguchi methods have the advantage of investigating the effects of a number of variables and the interactions between them in a single experiment containing a few reactions. In this study the optimal cutting condition for work piece milling was selected Makino FDNC 86 vertical profile milling machine MAKINO FDNC 86 by varying cutting parameters through the Taguchi parameter design method. With the L3(9) orthogonal array, a total of 9experimental runs, covering three main factors each at three levels and three noise factors each at three levels as spindle speed, feed rate, depth of cut and analysis by Taguchi parameter design was an efficient way of determining the optimal cutting parameters for material aluminum alloy. Feed rate (F.R) is the most significant factor depends on MRR. The recommended parametric combination for optimum material removal rate is S.S (800/900/1000) F.R (100) D.O.C (0.2) but surface roughness different as recommended parametric combination for optimum is S.S (900) F.R (100) D.O.C (0.2). This was accomplished with a relatively small number of experimental runs, given the number of control and noise factors, suggesting that Taguchi parameter design is an efficient and effective method for optimizing surface roughness in a milling operation.

\section{REFERENCES}

[1] M. T. Hayajneh, M. S. Tahat, J. Bluhm (2007), "A study of effects of machining parameters on the surface roughness in the end milling process", Jordan Journal of Mechanical and Industrial Engineering, vol. 1, no. 1, pp. 1-5.

[2] B. Singh, R. Khanna, K. Goyal, P. Kumar (2013), "Optimization of input process parameters in CNC Milling machine of EN24 steel", International Journal of Research in Mechanical Engineering and Technology, vol. 4, Issue-1.

[3] M. Y. Kumar, Dr. G. Shankuraiah (2013), "Cutting parameters optimization in milling of P-20 tool steel and EN31B", IOSR Journal of Mechanical and Civil Engineering, vol. 8, Issue-5, pp. $38-47$.

[4] Julie Z. Zhang, Joseph C. Chenb, E. Daniel Kirby b'Surface roughness optimization in an end-milling operation using the Taguchi design Method' Journal of Materials Processing Technology 184 (2007) 233-239.

[5] Dalgobind Mahto And Anjani Kumar," Optimization of Process Parameters in Vertical CNC Mill Machines Using Taguchi's Design of Experiments", Ariser Vol. 4 No. 2 (61-75,2008

[6] Tao Ye, Cai-Hua Xiong," Geometric Parameter Optimization In Multi-Axis Machining”, Computer- Aided Design 40 (2008) 879890,2008 .

[7] Meng, Q., Calculation of optimum cutting condition for turning operation using a machining theory, Int. J. Mach. Tool Manuf. 40, $1709-17332000$.

[8] A. A. Thakare (2013), "Optimization of milling parameters for minimizing surface roughness using taguchi's approach", International Journal of Engineering Technology and Advanced Engineering, vol. 3, Issue-6.

[9] Amit Joshi \&Pradeep Kothiyal Investigating Effect of Machining Parameters of CNC Milling on Surface Finish by Taguchi Method International Journal on Theoretical and Applied Research in 
Mechanical Engineering (IJTARME) ISSN ISSN : 2319 - 3182, Volume-2, Issue-2, 2013.

[10] Krishankant, JatinTaneja, MohitBector, Rajesh Kumar" Application of Taguchi Method for Optimizing Turning Process by the effects of Machining Parameters" International Journal of Engineering and Advanced Technology (IJEAT) ISSN: 2249 8958, Volume-2, Issue-1, October 2012.

[11] Mandeep Chahal" Investigations of Machining Parameters on Surface Roughness in CNC Milling using Taguchi Technique" Vol.4, No.7, 2013 - National Conference on Emerging Trends in Electrical, Instrumentation \& Communication Engineering, ISSN $2222-1727$

[12] Z.Z. Julie, C.C. Joseph, E.D. Kirby, Surface roughness optimization in an end-milling operation using the Taguchi design method, J. Mater. Process. Technol. 184 (2007) 233-239.
[13] J.A. Ghani, I.A. Choudhury, H.H. Hassan, Application of Taguchi method in the optimization of end milling parameters, J. Mater. Process. Technol. 145 (2004) 84-92.

[14] Kivak, Turgay. "Optimization of surface roughness and flank wear using the Taguchi method in milling of Hadfield steel with PVD and CVD coated inserts." Measurement 50 (2014): 19-28.

[15] J.T. Horng, N.M. Liu, K.T. Chiang, Investigating the machinability evaluation of Hadfield steel in the hard turning with Al2O3/TiC mixed ceramic tool based on the response surface methodology, J. Mater. Processing Technol. 208 (2008) 532541. 